\title{
Inelastic Lateral-Torsional Buckling Load on Fixed Circular Channels Arches Under Transverse Point Load
}

\author{
Emmanuel-Peters Teke Tebo ${ }^{1, *}$
}

ORCID: 0000-0003-4926-8828

\author{
Leonard Masu'
}

ORCID: 0000-0002-8544-6321
Patrick Nziu ${ }^{3}$

ORCID: 0000-0002-5899-0700

\author{
${ }^{1,2,3}$ Department of mechanical engineering, Vaal University of Technology, Andries Potgieter Blvd, \\ Vanderbijlpark, 1900, Gauteng, South Africa.
}

\begin{abstract}
The purpose of this study was to determine the effects of inelastic Lateral-Torsional Buckling (LTB) loads and their behavior on fixed circular aluminium channel arches under transverse point load at the shear centre. A total of 55 arch models were developed and analyzed using a three-dimensional Finite Element Analysis (FEA) commercial software called Abaqus. The analyses were based on the combination of inelastic imperfection variables consisting of material nonlinearity, geometric imperfection, and residual stresses using two design approaches. The first approach used a constant span length having various channel profiles. Whereas, in the second approach different constant slender ratios with a single channel profile was analyzed. The prebuckling results generated using FEA method showed good agreement with those computed using existing analytical solutions. In addition, variations in web-flange thickness, web height, and slender ratios have been shown to significantly impact the magnitude of the buckling load. Besides, profiles with high torsion constant were found to be more resistant to LTB. In addition, it was established that arches developed from single channel profile having a low constant slender ratio have high resistance against LTB. On the other hand, arches formed at constant span length, with included angles of $50^{\circ} \leq 2 \alpha \leq 90^{\circ}$ designated as moderated were found to be more suitable for the designs against LTB than those referred as shallow with $2 \alpha<50^{\circ}$. The least resistance was noted at $90^{\circ}<2 \alpha \leq 180^{\circ}$ arches normally denoted as deep. In contrast, for arches developed at a constant slender ratio, the respective order of high resistivity to LTB was categorized as follows, $90^{\circ}<2 \alpha \leq 180^{\circ}, 50^{\circ} \leq 2 \alpha \leq 90^{\circ}$ and $2 \alpha<50^{\circ}$.
\end{abstract}

Keyword: circular fixed arches, inelastic lateral-torsional buckling, shear centre, transverse point load, imperfections, prebuckling, shallow, moderate and deep arches

\section{INTRODUCTION}

Lateral-torsional buckling (LTB) on freestanding circular arches of open thin-walled sections have been studied extensively over the years ( $\mathrm{Lu}$ et al., 2019; Tebo et al., 2020). Most of the existing studies focused on arches with pinned ends or fixed ends subjected to uniform compressive force and bending moment (Bradford et al., 2005). These initial studies assumed trivial prebuckling state of stress making their analyses less complicated (Pi \& Bradford, 2004a). Though, a subsequent study conducted by Pi et al. (2010) revealed that the state of prebuckling stress for arches subjected to central concentrated load (CCL) are non trivial. The analysis of nontrivial arches is based on non-uniform prebuckling state of stress which entails complex stress distribution patterns making the process of generated the solutions cumbersome. This complexity of analysis has hindered the development of more studies on arches, particularly on fixed ends arches subjected to CCL that generates combined axial compressive and bending actions (Liu et al. 2017).

With few studies reported on the LTB of fixed end circular arches subjected to CCL, it was realized that majority of the reviewed studies were based on the elastic LTB, as cited by Liu et al. (2017). Although, there is great likelihood that elastic analyses may over or underestimate the LTB loads. Because the effects of imperfections variables such as material nonlinearity, geometric imperfections, and residual stresses on the LTB are neglected. A study by Pi and Trahair (2000) showed that taking into account the effects of residual stresses and initial geometric imperfections might reduce the buckling strength by up to $11 \%$ and $30 \%$, respectively. Besides, most of the reviewed studies were carried out on double symmetric I-sections, whose structural designs cannot be applied on monosymmetric sections like channels (BSI, 2007). This drawback limits the options of the designers to utilize advantages associated with such profiles such as high performance and less weight (Kim, Min, \& Su, 2000a).

Handful studies on the inelastic analyses (also referred to as elastic-plastic) of fixed end circular arches subjected to CCL have been reported (Spoorenberg, 2011). Pi and Bradford (2003) developed a rational 3D nonlinear finite curved beamelement model to predict solution for elastic, elastic-plastic and post-buckling LTB analyses. These solutions were applied on double symmetric I-sections arches subjected to CCL with both fixed and pinned supports. The arches were made from steel and aluminium (Al) alloy materials. Later Pi and Bradford, (2005) advanced on their aforesaid initial study and proposed general stability design solutions to determine the out-of-plane buckling for fixed end circular steel I-section arches. The study took into consideration the effects of initial out-of-plane crookedness and residual stresses. Other studies by Spoorenberg et al. (2012)

\footnotetext{
${ }^{*}$ Corresponding Author.
} 
and Guo et al. (2015) used experimental techniques to investigate the effects of out-of-plane stability and inelastic buckling strength on fixed end circular steel arches. The two studies concluded that these geometric imperfection variables have significant impact on the buckling load. Regrettably, there is no exhaustive information on the effects of out-of-plane and in-plane on the behaviour and magnitude of LTB load in fixed aluminium alloy channel arches. This observation is a drop back against the increased worldwide sensitization on the importance of using green materials in structural designs such as aluminium alloys as opposed to other alternatives like steel alloys (Tebo et al., 2020).

Therefore, the objective of this paper was to investigate the inelastic LTB load and behaviour of freestanding fixed ends circular channel arches, developed from structural aluminium grade 6061-T6 alloy subjected to a transverse point load at the shear centre.

\section{METHODOLOGY}

Two design approaches were used to achieve the objectives of this work. The inelastic analyses carried out were based on a combination of imperfection variables consisting of material nonlinearity, geometric imperfection, and residual stresses. In the first approach, the arches were developed at a constant span length using different channel profiles to evaluate the influence of variation in web-flange thickness and web height on the LTB stability. While on the second approach, arches were developed at different constant slender ratios using single channel profiles to evaluate the effects of change in slender ratios on the LTB loads. Eventually, optimal designs against LTB in respect to the included angles were determined using the two design approaches.

\subsection{Cases studied}

Owing to structural $\mathrm{Al}$ widespread use in structures, alloy 6061-T6 was selected for this case study (Wang et al., 2012). The Al profile catalogue from Hulamin Extrusions (2015) was used to select three Al channel profiles with part numbers 16831, 16825, and 16045 for this study. The profiles were selected within class 1 , and 2 as categories reported by Mazzolani, (2004). A sample of the investigated channel crosssection is shown in Figure 1.
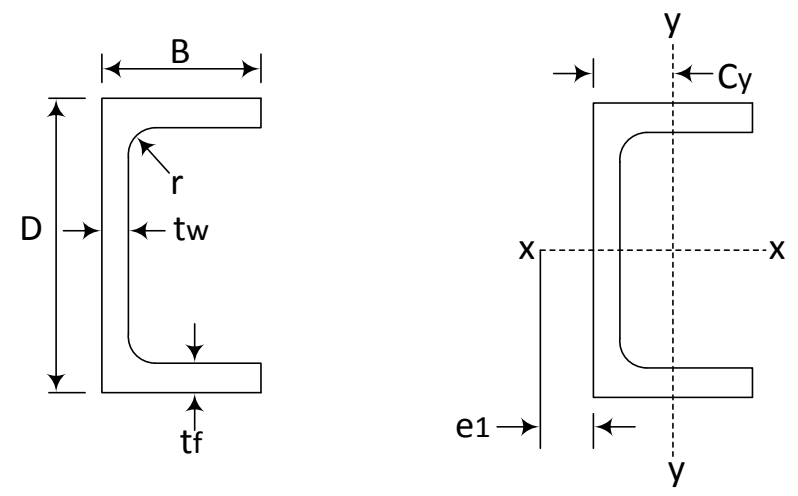

Figure 1: The aluminium channel cross-section representation
Whereby $D$ is the height of the web, $B$ is the flange width, $t_{f}$ is the flange thickness, $t_{w}$ is web thickness, $r$ is the inner radius of the web and flange, $e_{l}$ is the position of the shear centre, and $C_{y}$ is the position of the centre of gravity. Table 1 outlines the detailed description of the selected channel cross-sections based on the given parameters in Figure 1.

Table 1: Complete summary of the cross-sections examined as per Figure 1 (Hulamin Extrusions, 2015)

\begin{tabular}{|l|c|c|c|}
\hline Cross-section profiles & $\begin{array}{c}\text { Profile } \\
1\end{array}$ & $\begin{array}{c}\text { Profile } \\
2\end{array}$ & $\begin{array}{c}\text { Profile } \\
3\end{array}$ \\
\hline Profile number & 16045 & 16825 & 16831 \\
\hline Cross-section classification & Class 2 & Class 1 & Class 1 \\
\hline Height of the web (D) in mm & 25.4 & 25.4 & 38.1 \\
\hline Width of the flange $(B)$ in mm & 12.7 & 12.7 & 12.7 \\
\hline $\begin{array}{l}\text { Web and flange thickness } \\
\left(t_{w} \& t_{f}\right) \text { in mm }\end{array}$ & 1.6 & 3.18 & 3.18 \\
\hline$r(\mathrm{~mm})$ & 0.64 & 0.4 & 0.3 \\
\hline$e_{1}(\mathrm{~mm})$ & 3.6 & 2.5 & 2 \\
\hline$C_{y}(\mathrm{~mm})$ & 3.8 & 4.3 & 3.7 \\
\hline
\end{tabular}

The Al channel profiles presented in Table 1 were used to model freestanding circular fixed ends arches. The included angle was varied for each model.

\section{$2.2 \quad$ Numerical method}

The numerical method employed in this study is the Finite Element Analysis (FEA). Thanks to its ability to perform inelastic and elastic analyses that minimize errors if one wishes to compare the elastic and inelastic results. Furthermore, the FEA method has for years been a more convenient and reliable tool for investigating among other factors the imperfections influence on the LTB of arches (Liu et al., 2017a; Spoorenberg, 2011). The imperfections were applied using the geometric and material nonlinear imperfection analysis (GMNIA) approach.

\subsubsection{Modelling}

A total of 55 3-D FEA models were analyzed using the standard Abaqus/CAE. The first group comprised of 33 arch models with 11 models from each profile, formed at a constant period length $L=500 \mathrm{~mm}$. While the second group comprised of 22 arch models developed from profile 16825 at constant slender ratios $S / r_{x}=60$ and 90 (where $\mathrm{S}$ is the arc length and $\mathrm{r} \mathrm{x}$ is the gyration radius around the main axis). Profile 16825 was used to develop arches at constant slender ratios due to the profile mean cross-section dimension properties when compared to profiles 16045 and 16831 presented in Hulamin Extrusions (2015). 


\subsubsection{Part creation}

A 3D space, deformable type, with the base feature of shell shape and sweep type, were utilized among other essential built-in modelling options in Abaqus to create the part models investigated in this study. Figure 2 represents the sample of a part created.

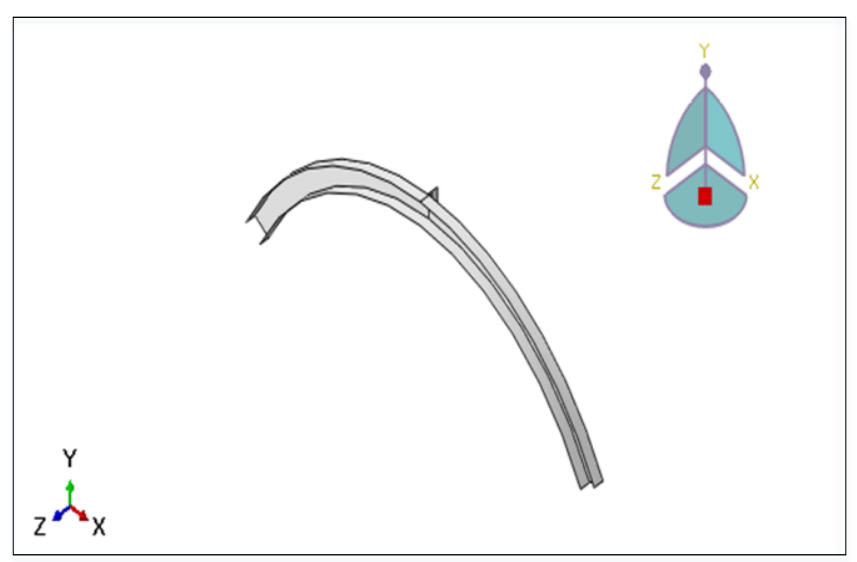

Figure 2: Sample part model

\subsubsection{Material properties}

The mechanical properties of 6061-T6 Al alloys specified by the Aerospace Specification Metals Inc, (2012) used in this study were as follows; Young modulus $E=68.9 \mathrm{GPa}$, and Poisson's ratio of 0.33 were used to represent the elastic properties of the material. On the other hand, the bi-linear elastic-plastic stress-strain curve was used to apply the material nonlinearity. For the bi-linear material curve, the tensile yield strength $f_{y}=276 \mathrm{MPa}$, ultimate tensile strength $f_{\text {ult }}=$ $310 \mathrm{MPa}$, and $0.2 \%$ proof stress were used to define the plasticity of the material.

\subsubsection{Load and boundary conditions}

To obtained out-of-plane and in-plane fixed condition at the supports, the encastre boundary condition in Abaqus was used as it guarantees no displacement and rotation in the $\mathrm{x}, \mathrm{y}$, and z-directions, thereby rendering the supports completely fixed. The concentrated load was applied in the y-directions at the shear centre, acting downward. Because no load constraints were imposed, the load was free to travel in the $\mathrm{x}$ and $\mathrm{z}$ directions based on the deformation taking place. In real application, such point load can be applied by using tie down masses.

\subsubsection{Model meshing}

A three-dimensional, quadrilateral, four-node, stress/displacement, double curved general-purpose shell element (S4R) with six degrees of freedom was used at all nodes. The element type was used as it is known to provide accurate analysis results for thinwalled members and it is suitable for research involving finite membrane strains and large rotations (Valeš \& Stan, 2017). On the other hand, a small fine mesh of $2 \mathrm{~mm}$ having six elements on each flange with eight and thirteen elements on the web of profile 16825 and 16831 respectively was selected for optimum mesh convergence. A sample of the finite element (FE) arch model is shown in Figure 3.

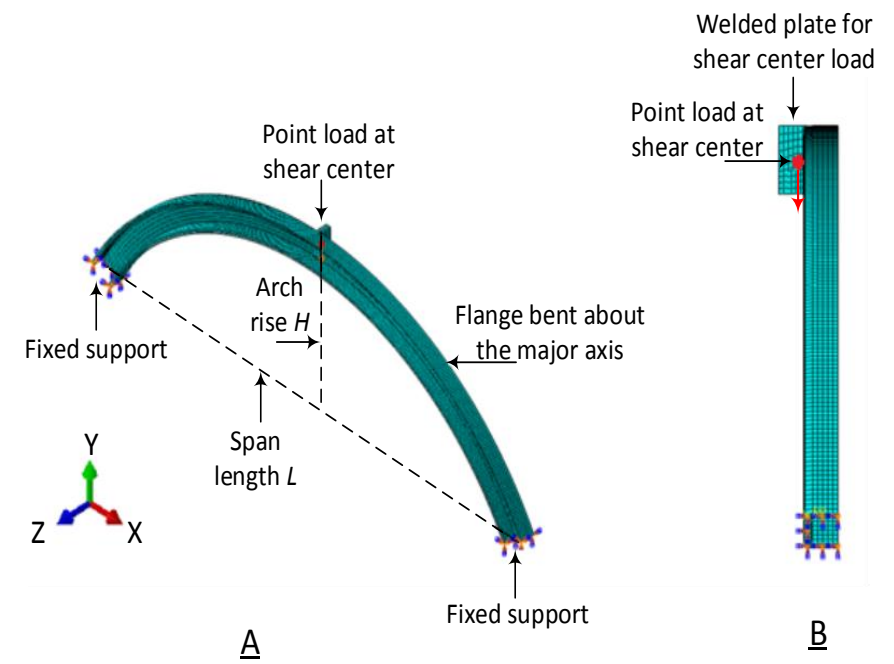

Figure 3: A sample of the finite element arch model (A) isometric view (B) side view B

\subsubsection{Imperfections}

The imperfections considered in this study comprised the material nonlinearities, initial geometric imperfections, and the residual stresses combined. The material nonlinearities were represented with the bi-linear elastic-plastic stress-strain curve. The maximum imperfection $e=S / 1000$ recommended by Spoorenberg (2011) for rolled bend arches was used for the geometric imperfection. Meanwhile, the residual stress model presented by Snijder et al., (2008) for the channel section was implemented to represent the initial stress state of the arch models.

\subsubsection{Solving phase}

The nonlinear analyses performed in this study included the material nonlinear analysis (MNA) and GMNIA that used the Static Riks analysis technique in Abaqus. The Static Riks method was employed due to its reliability to solve problems in GMNIA and imperfection-sensitive structures as reported by Sadowski, Fajuyitan, and Wang (2017) and Ellobody, Feng, and Young (2014) studies.

Further, the results generated from the MNA method were used to validate the FE model. That is the elasto-plastic prebuckling analyses that were used to generate axial compressive forces and bending moments. Whereas the GMNIA technique was used to determine the inelastic LTB buckling load also referred to as the ultimate buckling load $F_{u l t}$. 


\subsection{Validation of the finite element model}

The theoretical solutions proposed by Pi and Bradford (2003) study were used to validate the FE model. As there were no available exact or theoretical solutions for fixed channel arches subjected to central concentrated load. The I-sections used for validating the FE model were developed under the similar conditions to those of the channel section, as detailed in section 2.1. The point of interest used for the validation was at the crown were the maximum axial compressive force and bending moment occurred.

The cross-section dimensional properties of the double symmetric $\mathrm{Al}$ I-section used to validate the FE model are given in Table 2. The $30^{\circ}, 50^{\circ}, 70^{\circ}, 90^{\circ}$, and $120^{\circ}$ included angles were used due to the computational time involved with nonlinear analyses.

\section{RESULTS AND DISCUSSION}

In this section, the findings obtained by the different methods mentioned in the previous section are presented and addressed in the three subheadings that follows.

\subsection{Preliminary validation of results}

Analytical and FEA findings were compared using graphs. That is, the dimensionless axial compressive force $\left(N_{m} / N_{Y}\right)$ and bending moment $\left(M_{m} / M_{P}\right)$ are plotted at the ordinates, and the included angles $(2 \alpha)$ at the abscissa. Figure 4 shows the inelastic comparison plots for the different variables.

Table 2: I-section dimensional properties

\begin{tabular}{|l|c|}
\hline Cross-section description & Dimensions \\
\hline Width $D$ & $15.82 \mathrm{~mm}$ \\
\hline Flange width $B$ & $7.04 \mathrm{~mm}$ \\
\hline Flange thickness $t_{f}$ & $1.42 \mathrm{~mm}$ \\
\hline Web thickness $t_{w}$ & $1.38 \mathrm{~mm}$ \\
\hline Mean radius of the arch $R$ & $500 \mathrm{~mm}$ \\
\hline Point of the applied load from Shear centre $y_{p}$ & $-7.91 \mathrm{~mm}$ \\
\hline Load applied $F$ & $1 \mathrm{~N}$ \\
\hline
\end{tabular}

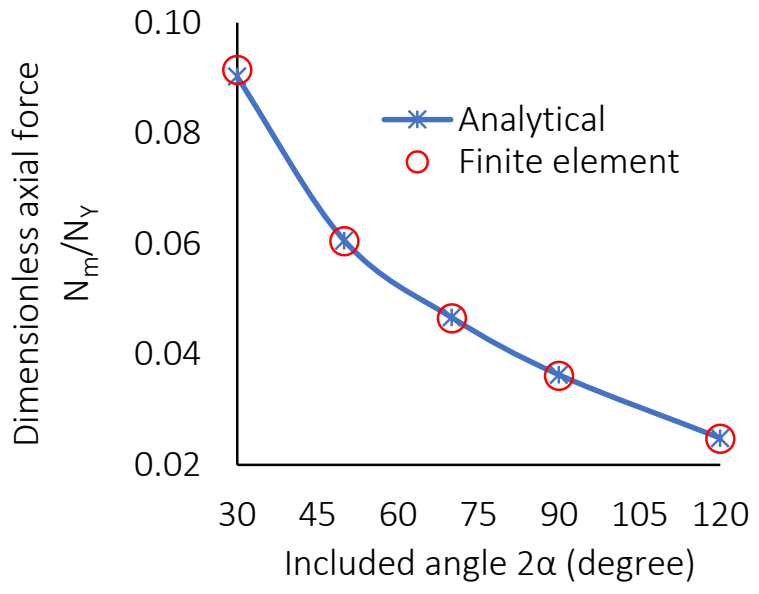

(A)

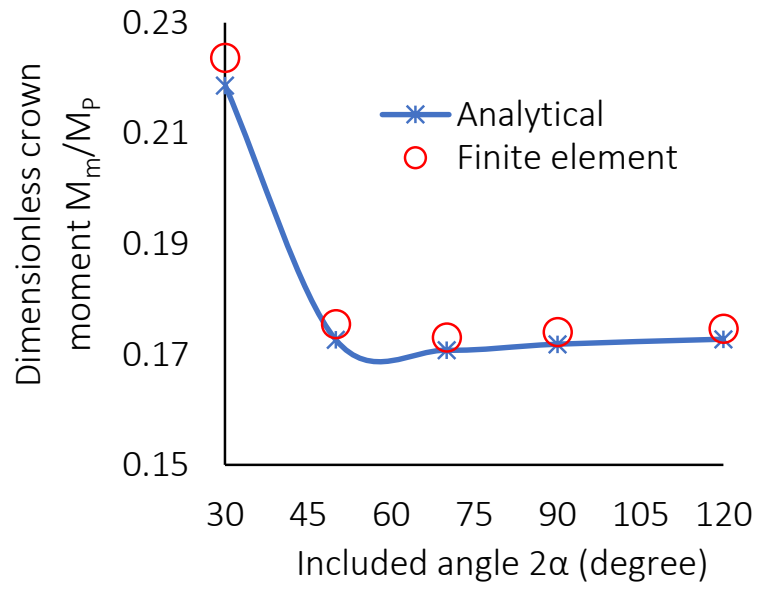

(B)

Figure 4: Comparison of the finite element and theoretical (A) axial compressive force and (B) bending moment at the crown at various included angles

It can be seen in Figure 4 that despite the insignificant variants between the results, slightly noticeable differences were observed in part (B). Nevertheless, the maximum percentage error obtained was $13 \%$, with the majority below $5 \%$. From the different observations, it was concluded that the inelastic FE model was accurate enough to be used to investigate circular fixed ends arches under transverse point load. 


\subsection{Presentation and discussion of prebuckling results}

The inelastic axial compressive force and central bending moment results obtained from profiles 16045,16825 and 16831 at constant span length $(L)$ and profile 16825 for constant slender ratio $\left(S / r_{x}\right)$ at included angles $2 \alpha$ are presented in this section.

\subsubsection{The inelastic axial compressive force}

Inelastic axial compressive forces produced by arches established at the $500 \mathrm{~mm}$ constant span length $(L)$ were evaluated singly from those formed at constant slender ratios $S / r_{x}=60$ and 90 .

\subsubsection{Axial compressive forces of arches developed at constant span length}

Profiles 16045, 16825, and 16831, as described in Table 1, were used in this section to evaluate the impact of change in web-flange thickness and web height on the inelastic axial compressive force behaviour and magnitudes. The arches were developed at $L=500 \mathrm{~mm}$. The graph in Figure 5 presented a typical variation of the inelastic dimensionless axial compressive force at the crown $\left(N_{m} / N_{Y}\right)$ at included angles $2 \alpha$.

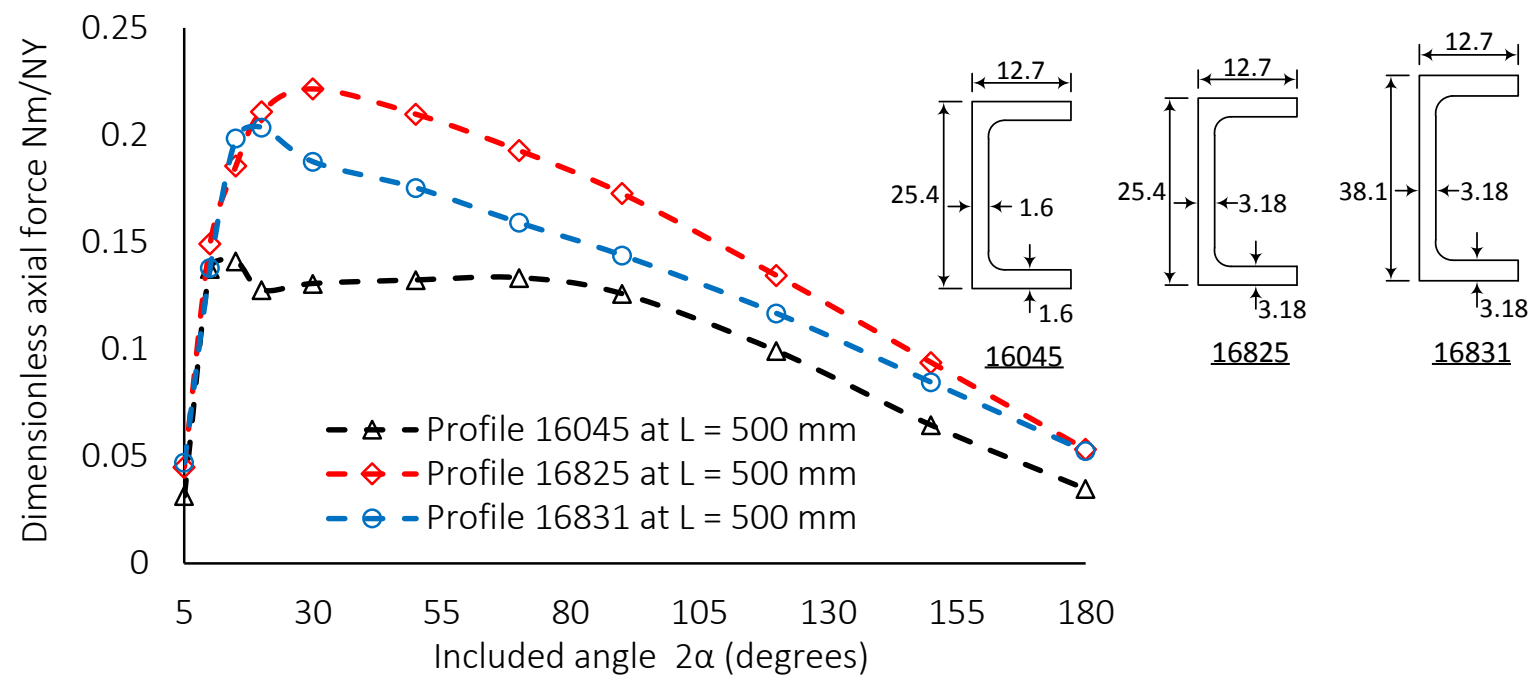

Figure 5: Cross-sections variations of the axial compressive force with included angles

As demonstrated in Figure 5, all the cross-sections, the $N_{m} / N_{Y}$ values increased drastically to some maximum values before decreasing with increase in the included angle. In reference to profile 16825, the observed behaviour change of profile 16045 after its peak value was associated with the effect of the imperfection's sensitivity that developed high bending stresses at included angles $20^{\circ} \leq 2 \alpha \leq 30^{\circ}$. Also, based on the inelastic axial compressive forces impacts on the LTB load, one would expect profile 16825 to have the most LTB load due to its overall high $N_{m} / N_{Y}$ values (Pi \& Bradford, 2003).
However, this may not be the case for such arches, as their slender ratio is not constant. Thus, the torsion constant turns to have a highly significant effect on the LTB load resistance. It should be noted that a decrease in the LTB load would still be expected at includes angles $10^{\circ} \leq 2 \alpha \leq 30^{\circ}$ for all three profiles due to the high inelastic axial compressive forces as reported in similar study by $\mathrm{Pi}$ and Trahair (1996). Nonetheless, the maximum and minimum $N_{m} / N_{Y}$ values are summarized in Table 3. Profile 16825 curve was used as the reference curve due to its mean dimension properties.

Table 3: Maximum and minimum $N_{m} / N_{Y}$ values at their respective included angles and percentage difference for arches developed at constant span length

\begin{tabular}{|c|c|c|c|c|c|c|c|}
\hline \multicolumn{2}{|c|}{$\begin{array}{c}\text { Profile description } \\
\text { (dimensions in mm) }\end{array}$} & $\begin{array}{c}\text { Maximum } N_{m} / N_{Y} \text { and } \\
\text { corresponding included } \\
\text { angle } 2 \alpha\end{array}$ & \multicolumn{2}{c|}{$\begin{array}{c}\text { Minimum } N_{m} / N_{Y} \text { and } \\
\text { corresponding included angle } 2 \alpha\end{array}$} & $\begin{array}{c}\text { Maximum } N_{m} / N_{Y} \\
\text { percentage difference } \\
\text { at corresponding } \\
\text { included angle } 2 \alpha(\%) \\
\text { Ref. } 16825\end{array}$ \\
\hline Profile & $\begin{array}{c}\text { Web \& } \\
\text { flange } \\
\text { thickness }\end{array}$ & Web height & $N_{m} / N_{Y}$ & $2 \alpha\left(^{\circ}\right)$ & $N_{m} / N_{Y}$ & $2 \alpha\left(^{\circ}\right)$ & 5 \\
\hline 16825 & 3.18 & 25.4 & 0.221 & 30 & 0.045 & 5 & 5.4 \\
\hline 16045 & 1.6 & 25.4 & 0.141 & 15 & 0.031 & 5 & 5 \\
\hline 16831 & 3.18 & 38.1 & 0.203 & 20 & 0.047 & 5 & 84.4 \\
\hline
\end{tabular}


It can be seen from Table 3 that all three profiles attained their maximum $N_{m} / N_{Y}$ values at different included angles but the minimum $N_{m} / N_{Y}$ values at $2 \alpha=5^{\circ}$. Also, it was revealed that by decreasing the web-flange thickness by half, that is from profile 16825 to 16045 reduces the inelastic axial compressive force by $44.4 \%$ at a corresponding included angle. Meanwhile, an increase of the web height by $66.7 \%$, which is from profile 16825 to 16831 , decreases the axial compressive force by only $8.8 \%$ at the corresponding included angle. Again, the axial compressive forces behaviours happened to be insignificantly influenced by the web-flange thickness and web height, but rather the magnitudes. Thus, the $N_{m} / N_{Y}$ overall behavioral trend was similar to those reported for arches developed at constant slender ratio reported in Pi and Bradford (2003) research work.

\subsubsection{Axial compressive forces of arches developed at constant slender ratios}

The profile 16825 was used to investigate the effects of the slender ratios on the inelastic axial compressive forces' behaviour and magnitudes. The investigated slender ratios $\left(S / r_{x}\right)$ were 60 and 90 . Typical variation of the inelastic dimensionless axial compressive forces at the crown $\left(N_{m} / N_{Y}\right)$ at included angles $(2 \alpha)$ are presented in Figure 6.

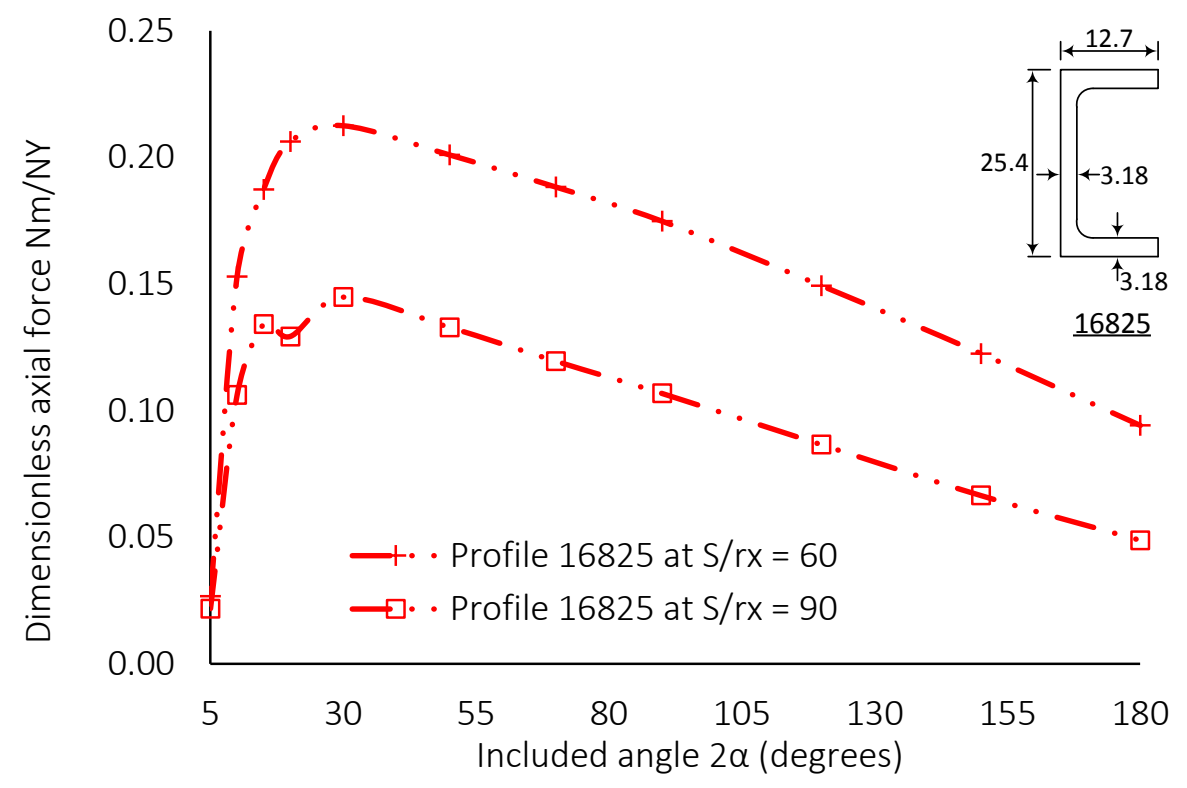

Figure 6: Slender ratios variations of the axial compressive force with included angles

From Figure 6, it can be seen that with a continuous increase of the included angles, the $N_{m} / N_{Y}$ values for arches developed at $S / r_{x}=60$ increased to some peak values and then decreased continuously. While arches developed at $S / r_{x}=90$, showed a similar behaviour with a small variance between $10^{\circ} \leq 2 \alpha \leq$ $30^{\circ}$. The small variance of slight decrease and increase was associated with early yielding that occurred on a shallow slenderer arch coupled with the effect of the included angles. Based on Pi and Bradford (2003) study, one should expect the
$S / r_{x}=60$ arches to have the most resistance against LTB, due to their overall high $N_{m} / N_{Y}$ magnitudes. Furthermore, at $2 \alpha=$ $30^{\circ}$, where the inelastic axial compressive forces are maximum, a decrease in the LTB load should be expected. That said, the maximum and minimum $N_{m} / N_{Y}$ values at their respective included angles are summarized in. The curve for arches developed at $S / r_{x}=60$ was used as the reference curve to determine the percentage deviation due to its overall high $N_{m} / N_{Y}$ values.

Table 4: Maximum and minimum $N_{m} / N_{Y}$ values at their respective included angles and percentage difference for arches developed at the constant slender ratio of 60 and 90

\begin{tabular}{|c|c|c|c|c|c|}
\hline \multirow{2}{*}{$\begin{array}{c}\text { Slender ratio } \\
S / r_{x}\end{array}$} & \multicolumn{2}{|c|}{$\begin{array}{c}\text { Maximum } N_{m} / N_{Y} \text { and } \\
\text { corresponding included angle } 2 \alpha\end{array}$} & \multicolumn{2}{|c|}{$\begin{array}{c}\text { Minimum } N_{m} / N_{Y} \text { and } \\
\text { corresponding included angle } 2 \alpha\end{array}$} & $\begin{array}{c}\text { Maximum } N_{m} / N_{Y} \text { percentage } \\
\text { difference at corresponding } \\
\text { included angle 2 } \alpha(\%), R e f: \\
S / r_{x}=60\end{array}$ \\
\cline { 2 - 5 } & $N_{m} / N_{Y}$ & $2 \alpha\left(^{\circ}\right)$ & $N_{m} / N_{Y}$ & $2 \alpha\left(^{\circ}\right)$ & 5 \\
\hline 60 & 0.212 & 30 & 0.0267 & 5 & 5 \\
\hline
\end{tabular}


From Table 4, it can be seen that the maximum and minimum $N_{C} / F$ values for both slender ratios occurred at $2 \alpha=30^{\circ}$, and $5^{\circ}$, respectively. These similarities implied that the included angle at which the maximum and minimum $N_{m} / N_{Y}$ occurred was not influenced by the slender ratios. Moreover, the $37.8 \%$ difference between the maximum $N_{C} / F$ value for arches developed at $S / r_{x}=60$, and the corresponding value of slender ratio 90 indicated how much the inelastic axial compressive force magnitudes could be influenced by increasing the slender ratio by $66.7 \%$.

\subsubsection{Inelastic bending moments}

The inelastic bending moments at the crown $M_{m}$ at included angles, $2 \alpha$ are reported in the same format to those of the axial compressive forces. That is for arches developed at $L=500$ $\mathrm{mm}$, and those developed at $S / r_{x}=60$ and 90 . The obtained results were plotted with the dimensionless bending moment at the crown $\left(M_{m} / M_{P}\right)$ as the ordinates and included angles $(2 \alpha)$ as the abscissa.

\subsubsection{Bending moments of arches developed at constant span length}

Like the axial compressive force, profiles 16045, 16825, and 16831 are used in this section to evaluate the impact of change in web-flange thickness and web height on the inelastic bending moment behaviour and magnitudes. The arches were developed at constant span length of $L=500 \mathrm{~mm}$. The graph in Figure 7 presented a typical variation of the inelastic dimensionless bending moment at the crown against the included angles $(2 \alpha)$.

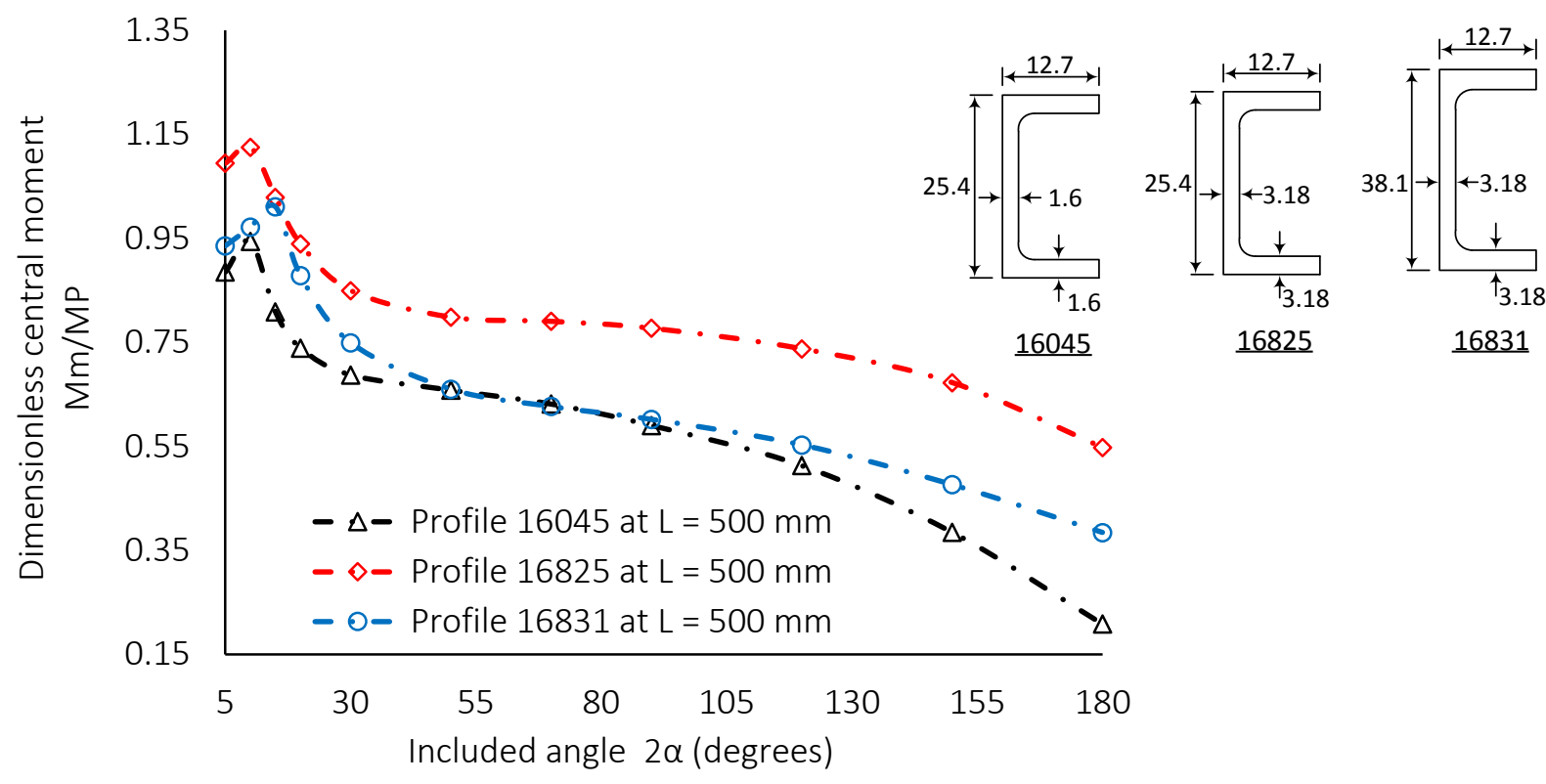

Figure 7: Cross-sections variations of the central bending moment with included angles

As illustrated in Figure 7, for all the profiles, as the included angles increased, the $M_{m} / M_{P}$ values first increased to their maximum, and then decreased to their minimum values. The differences in $M_{m} / M_{P}$ magnitudes noted among the three profiles could not be directly linked to any of their crosssections' properties presented in Hulamin Extrusions (2015) other than due to the influence of the imperfections coupled with the included angles. With an overall high $M_{m} / M_{P}$ values for profile 16825 , one would expect the profile to have more resistance to LTB, followed by profiles 16831 and 16045, in that order. This expectation, however, may vary for these arches developed at constant span length as other factors such as torsion constant vary for all the three profiles. Nonetheless, an increase in the LTB load should be expected at $10^{\circ} \leq 2 \alpha \leq$ $15^{\circ}$, where the inelastic bending moments increased to a maximum. Therefore, the maximum and minimum $M_{m} / M_{P}$ values at their respective included angles are presented in Table 5. Again, the profile 16825 curve was used as the point of reference to determine the percentage differences due to the profile mean dimensional properties. 
International Journal of Engineering Research and Technology. ISSN 0974-3154, Volume 13, Number 10 (2020), pp. 2851-2863

(C) International Research Publication House. https://dx.doi.org/10.37624/IJERT/13.10.2020.2851-2863

Table 5: Maximum and minimum $M_{m} / M_{P}$ values at their respective included angles and percentage difference for arches developed at constant span length

\begin{tabular}{|c|c|c|c|c|c|c|c|}
\hline \multicolumn{3}{|c|}{$\begin{array}{l}\text { Profile description (dimensions } \\
\text { in } \mathrm{mm} \text { ) }\end{array}$} & \multicolumn{2}{|c|}{$\begin{array}{c}\text { Maximum } M_{m} / M_{P} \text { and } \\
\text { corresponding included } \\
\text { angle } 2 \alpha\end{array}$} & \multicolumn{2}{|c|}{$\begin{array}{l}\text { Minimum } M_{m} / M_{P} \text { and } \\
\text { corresponding included } \\
\text { angle } 2 \alpha\end{array}$} & \multirow{2}{*}{$\begin{array}{c}\text { Maximum } M_{m} / M_{P} \text { percentage } \\
\text { difference at corresponding } \\
\text { included angle } 2 \alpha(\%) \text { Ref. } 16825\end{array}$} \\
\hline Profile & $\begin{array}{l}\text { Web \& } \\
\text { flange } \\
\text { thickness }\end{array}$ & $\begin{array}{l}\text { Web } \\
\text { height }\end{array}$ & $M_{m} / M_{P}$ & $2 \alpha\left(^{\circ}\right)$ & $M_{m} / M_{P}$ & $2 \alpha\left(^{\circ}\right)$ & \\
\hline 16825 & 3.18 & 25.4 & 1.125 & 10 & 0.548 & 180 & - \\
\hline 16831 & 3.18 & 38.1 & 1.01 & 15 & 0.383 & 180 & 10.8 \\
\hline 16045 & 1.6 & 25.4 & 0.945 & 10 & 0.208 & 180 & 17.5 \\
\hline
\end{tabular}

It was noted from Table 5, that profiles 16825 and 16045 attained their maximum $M_{m} / M_{P}$ values at $2 \alpha=10^{\circ}$, while profile 16831 maximum $M_{m} / M_{P}$ value was attained at $2 \alpha=$ $15^{\circ}$. The difference in included angle for profile 16831 was associated with the low bending stress developed due to the profiles' large surface area. However, the minimum $M_{m} / M_{P}$ values were attained for all the three profiles at $2 \alpha=180^{\circ}$. This occurrence was due to the high slender ratios for all three profiles, resulting in low bending stresses at the $180^{\circ}$ included angle. Also, it can be seen that by decreasing the web-flange thickness by $50 \%$, (that is from profile 16825 to 16045 ) may decrease the maximum $M_{m} / M_{P}$ value by $10.8 \%$. On the other hand, increase of the web height by $66.7 \%$, (that is from profile 16825 to 16831 ) may result in a $17.5 \%$ decrease of the maximum $M_{m} / M_{P}$ value at the same included angles.
Nevertheless, it was realized that the change in web-flange thickness and web height had a significant impact on the bending moment magnitudes rather than the general behaviour.

\subsubsection{Bending moments of arches developed at constant slender ratios}

Similar to the axial compressive force, profile 16825 was used to evaluate the effects of the slender ratios on the bending moment at the crown. The impact of slender ratios $S / r_{x}=60$ and 90 on the inelastic bending moment at the crown $\left(M_{m}\right)$ are presented in Figure 8. The graph in Figure 8 was plotted as a variation of the dimensionless bending moment at the crown $\left(M_{m} / M_{P}\right)$ at included angles $(2 \alpha)$.

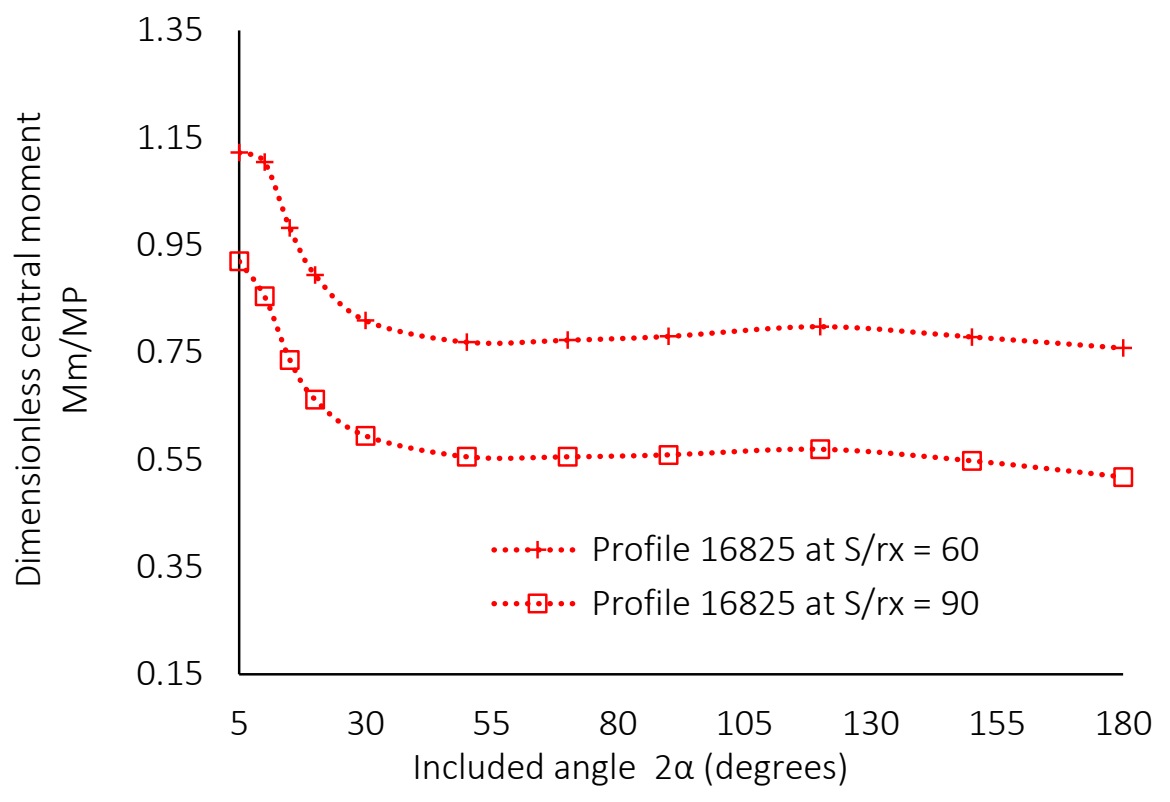

Figure 8: Slender ratios variations of the central bending moment with included angles

It was observed in Figure 8 that for both slender ratios, the maximum $M_{m} / M_{P}$ values first decreased significantly at $2 \alpha=$ $5^{\circ}$ to some values when $2 \alpha=30^{\circ}$. From included angles $2 \alpha>$ $30^{\circ}$, the $M_{m} / M_{P}$ values showed insignificant change in magnitudes as the include angle increased. It was also observed that arches developed at $S / r_{x}=60$ had an overall 
high magnitude $M_{m} / M_{P}$ values as compared to its counterparts modelled at $S / r_{x}=90$. The high magnitudes for arches developed at $S / r_{x}=60$ was due to the short arc length that made the arches less slender. For such arches, the expected LTB load should be higher, as reported by Pi and Bradford, (2003) study. Further, the maximum and minimum $M_{m} / M_{P}$ values for both slender ratios were attained at $2 \alpha=5^{\circ}$ and $180^{\circ}$. The difference between the maximum $M_{m} / M_{P}$ value for $S / r_{x}=60$ and their corresponding value for $S / r_{x}=90$ was $33 \%$. This occurrence revealed that by increasing the slender ratio by $66.7 \%$, the maximum inelastic bending moment at the crown would drop by $33 \%$ for the same included angle. Again, the change in slender ratio was noted to have significant influence on the bending moment magnitude as compared to the general behavior.

\subsection{Lateral-torsional buckling load-carrying capacity}

The effects of the change in web-flange thickness, web height, and slender ratios on the ultimate buckling load $\left(F_{u l t}\right)$ are investigated in this section. The first section presented the effects of the change in web-flange thickness and web height on the inelastic LTB loads at different included angles for arches developed at constant span length. Analogously, the next section presented the effects of slender ratios on the inelastic LTB load at different included angles for arches developed at constant slender ratios.

\subsubsection{Effects of cross-section dimensions on inelastic lateral-torsional buckling loads of arches developed at constant span length}

A typical variation of the $F_{u l t}$ values at included angles $2 \alpha$ for arches developed at $L=500 \mathrm{~mm}$ from profiles 16045,16825 and 16831 are presented in Figure 9.

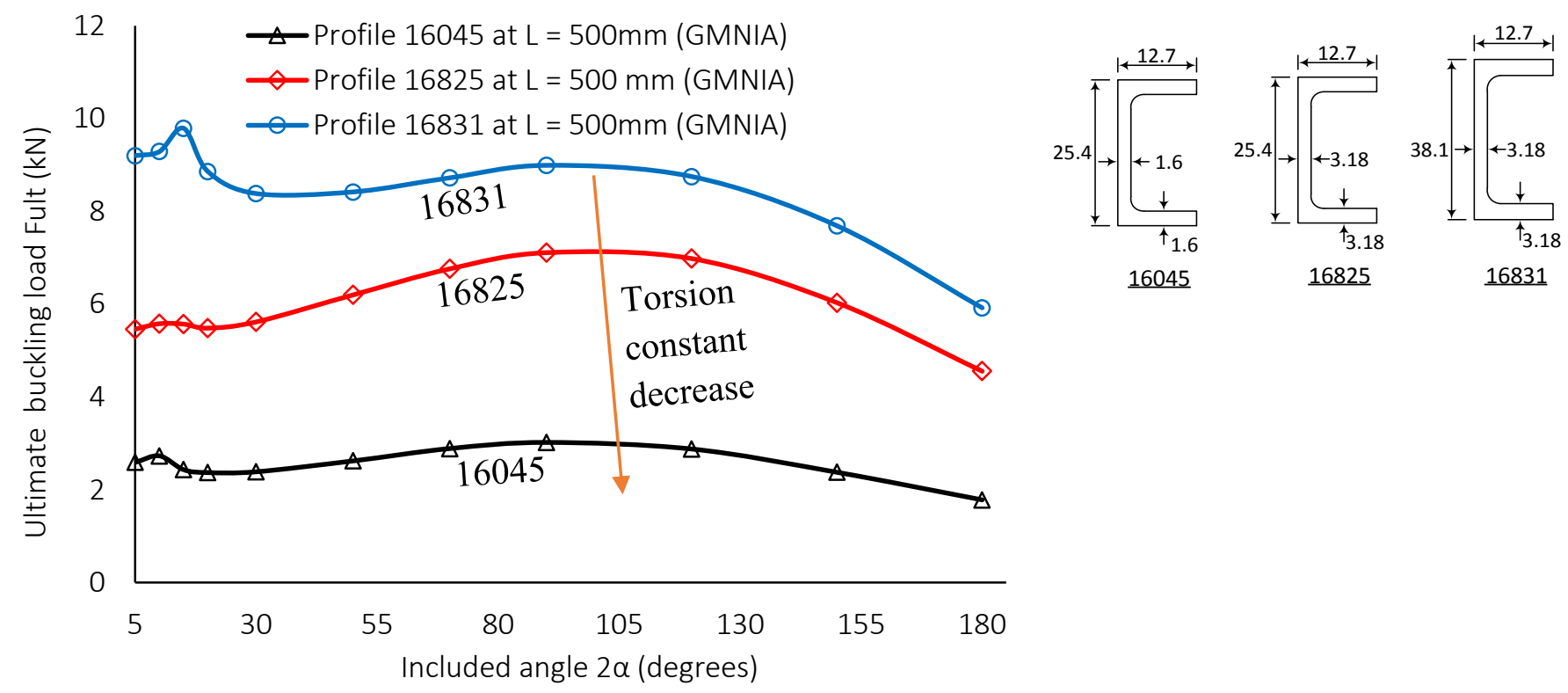

Figure 9: Cross-sectional effects on the inelastic lateral-torsional buckling load for fixed arches

As illustrated in Figure 9, all the $F_{u l t}$ values first increased, then slightly decreased, before increasing again and finally decreased gradually with increase in the included angles. These behavioral patterns were associated with the effects of the axial compressive forces and bending moments discussed in sections 3.2. On the hand, the $F_{u l t}$ overall differences in magnitudes were as a result of the torsion constant outlined in Hulamin Extrusions (2015). That is, profile 16831 had high magnitude of torsion constant. High magnitudes of torsion constant resulted to high resistance of LTB, making it more suitable for designs against LTB. Besides, the least LTB resistance occurred at the profile 16045 . The maximum and minimum $F_{\text {ult }}$ values at their respective included angles together with maximum percentage differences of the three profiles are summarized in Table 6 . Also, it is worthy to note that the curve of profile 16825 was used as the reference. Since the profile had mean dimensional properties. 
International Journal of Engineering Research and Technology. ISSN 0974-3154, Volume 13, Number 10 (2020), pp. 2851-2863

(C) International Research Publication House. https://dx.doi.org/10.37624/IJERT/13.10.2020.2851-2863

Table 6: Maximum and minimum $F_{\text {ult }}$ values at their respective included angles and percentage difference for arches developed at constant span length

\begin{tabular}{|c|c|c|c|c|c|c|c|c|c|}
\hline \multicolumn{3}{|c|}{$\begin{array}{l}\text { Profile description } \\
\text { (dimensions in } \mathrm{mm} \text { ) }\end{array}$} & \multicolumn{2}{|c|}{$\begin{array}{l}\text { Maximum } F_{u l t} \\
\text { and relative } \\
\text { included angle } 2 \alpha\end{array}$} & \multicolumn{2}{|c|}{$\begin{array}{c}\text { Minimum } F_{u l t} \\
\text { and relative } \\
\text { included angle } 2 \alpha\end{array}$} & \multirow{2}{*}{$\begin{array}{l}\text { Maximum } F_{\text {ult }} \\
\text { percentage difference at } \\
\text { relative included angle } \\
2 \alpha \text { in }(\%) \text { Ref. } 16825\end{array}$} & \multicolumn{2}{|c|}{$\begin{array}{c}\text { Maximum percentage } \\
\text { difference and relative } \\
\text { included angle } 2 \alpha \text { Ref. } \\
16825\end{array}$} \\
\hline Profile & $\begin{array}{l}\text { Web \& } \\
\text { flange } \\
\text { thickness }\end{array}$ & $\begin{array}{l}\text { Web } \\
\text { height }\end{array}$ & $\begin{array}{c}F_{\text {ult }} \text { in } \\
\mathrm{kN}\end{array}$ & $\begin{array}{l}2 \alpha \text { in } \\
\left({ }^{\circ}\right)\end{array}$ & $\begin{array}{c}F_{\text {ult }} \text { in } \\
\mathrm{kN}\end{array}$ & $\begin{array}{c}2 \alpha \text { in } \\
\left(^{\circ}\right)\end{array}$ & & $2 \alpha$ in $\left(^{\circ}\right)$ & $\%$ \\
\hline 16825 & 3.18 & 25.4 & 7.111 & 90 & 4.556 & 180 & - & - & - \\
\hline 16045 & 1.6 & 25.4 & 3.02 & 90 & 1.783 & 180 & 80.8 & 180 & 87.5 \\
\hline 16831 & 3.18 & 38.1 & 9.788 & 15 & 5.921 & 180 & 31.7 & 15 & 54.9 \\
\hline
\end{tabular}

As observed in Table 6 for profiles of the same flange width, as the web height is increased by $66.7 \%$, that is from profile 16825 to 16831 , the maximum LTB load would rise by $31.7 \%$ for the same included angle. For the same profiles, the maximum increase in LTB load at a corresponding included angle rose to $54.9 \%$. In case where the web-flange thickness is decreased by $50 \%$, that is from profile 16825 to 16045 , the LTB load would drop by up to $80.8 \%$. For the same decrease in thickness, the LTB load would rise to $87.5 \%$ at $180^{\circ}$ included angle. Nonetheless, it was revealed that for arches with web to flange widths ratio of 2 , that is profile 16825 and 16045 , the $90^{\circ}$ included angle would be ideal for designing against LTB for such arches. However, when the web to flange widths ratio is 3 , that is profile 16831 , the $15^{\circ}$ included angle becomes more suitable.

Nevertheless, the $180^{\circ}$ included angles stayed the least suitable for LTB designs for arches of constant span length due to their general low $F_{u l t}$ values for all three profiles. Again, the change in cross-section dimensions appeared to significantly influence the LTB load magnitudes as compared to the general behaviour across the included angles.

\subsubsection{Effects of slender ratios on inelastic lateral- torsional buckling loads of arches developed at the constant slender ratios}

The profile 16825 was used in this section to investigate the effects of the slender ratios on the ultimate buckling loads $\left(F_{u l t}\right)$ at respective included angles for arches developed at constant slender ratios. That said, a typical variation of the $F_{\text {ult }}$ obtained for arches developed at slender ratios $S / r_{x}=60$ and 90 at respective included angles $2 \alpha$ are presented in Figure 10.

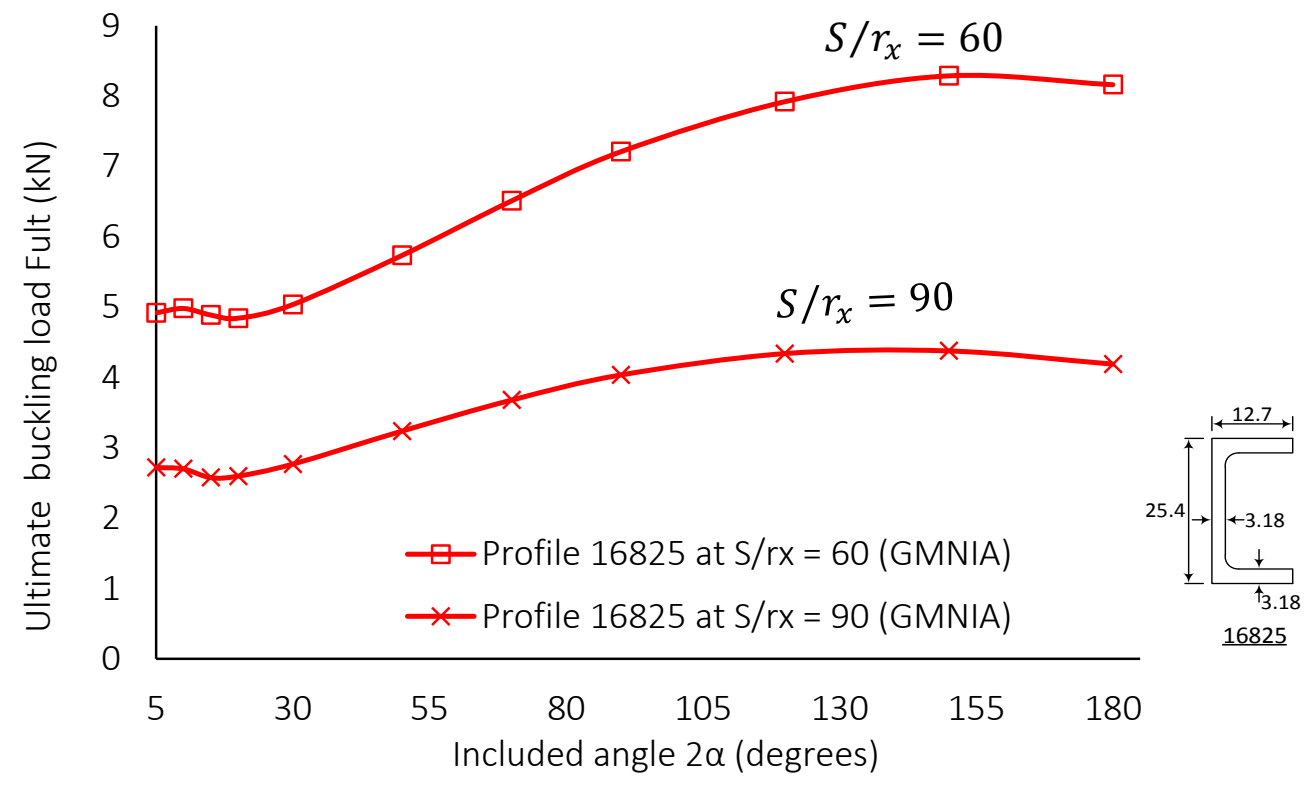

Figure 10: Slender ratios effects on the inelastic lateral-torsional buckling load for fixed arches 
As demonstrated in Figure 10, as the magnitude of included angles increased, a gradual decrease of the $F_{\text {ult }}$ values occurred before increasing to the peak values with a very slight decrease thereafter. The observed behavioral trends and overall magnitudes were similar to those of axial compressive forces and bending moments discussed in preceding section 3.2. The overall high $F_{u l t}$ values for arches developed at $S / r_{x}=60$ indicates that arches of lower slender ratios are more suitable in designs that require high LTB stability. That having been said, the maximum and minimum $F_{u l t}$ values at corresponding included angles together with their the maximum percentage differences are summarized in Table 7 . The $F_{\text {ult }}$ curve developed from arches modelled at $S / r_{x}=60$ was used as the reference to determine the difference in percentage on the ultimate load by change in slender ratio.

Table 7: Maximum and minimum values at their respective included angles and percentage difference for arches developed at constant slender ratios

\begin{tabular}{|c|c|c|c|c|c|c|c|}
\hline \multirow{2}{*}{$\begin{array}{l}\text { Slender } \\
\text { ratios } \\
\left(S / r_{x}\right)\end{array}$} & \multicolumn{2}{|c|}{$\begin{array}{l}\text { Maximum } F_{\text {ult }} \text { and } \\
\text { relative included angle } \\
2 \alpha\end{array}$} & \multicolumn{2}{|c|}{$\begin{array}{l}\text { Minimum } F_{u l t} \text { and } \\
\text { relative included } \\
\text { angle } 2 \alpha\end{array}$} & \multirow{2}{*}{$\begin{array}{c}\text { Maximum } F_{\text {ult }} \text { percentage } \\
\text { difference at relative } \\
\text { included angle } 2 \alpha \text { in }(\%) \\
\text { Ref. } S / r_{x}=60\end{array}$} & \multicolumn{2}{|c|}{$\begin{array}{l}\text { Maximum percentage difference } \\
\text { and relative included angle } 2 \alpha \\
\text { Ref. } S / r_{x}=60\end{array}$} \\
\hline & $F_{\text {ult }}$ in $\mathrm{kN}$ & $2 \alpha$ in $\left(^{\circ}\right)$ & $\begin{array}{c}F_{\text {ult }} \text { in } \\
\mathrm{kN}\end{array}$ & $2 \alpha$ in $\left(^{\circ}\right)$ & & $2 \alpha$ in $\left(^{\circ}\right)$ & $\%$ \\
\hline 60 & 8.287 & 150 & 4.843 & 20 & - & - & - \\
\hline 90 & 2.377 & 150 & 2.575 & 15 & 61.7 & 180 & 64.3 \\
\hline
\end{tabular}

From Table 7, it was noted that if the slender ratio is increased by $66.7 \%$, that is from 60 to 90 , the maximum LTB load would drop by $61.7 \%$ for the same included angle. However, for the same increase of the slender ratio, one should expect a $64.3 \%$ drop of the LTB load at $180^{\circ}$ included angle. In addition, it was revealed that for arches developed at constant slender ratio, the $150^{\circ}$ included angle would be more suitable for application in areas were high LTB occur due its high resistance to LTB. On the other hand, the shallow arches at included angles $15^{\circ} \leq$ $2 \alpha \leq 20^{\circ}$ were least favourable, due to their low resistance to LTB due to their low LTB loads. Again, the change in slender ratios is found to influence the LTB load magnitudes significantly as compared to the general behaviour across the included angles.

\section{CONCLUSION}

1. The good agreement between the finite element analyses (FEA) results and existing analytical solutions show that the FE models were reliable, efficient, and correct.

2. The change in web-flange thickness, web height, slender ratios, and included angles have a significant impact on the prebuckling magnitudes, and thus the buckling load.

3. The prebuckling overall magnitudes for individual profiles were found not to be relative to the overall buckling loads magnitudes but behaviour. That is, for shallow arches at $2 \alpha \leq 30^{\circ}$, the large compressive and bending moment developed prior to buckling, resulted to early buckling, thus low LTB resistance.

4. The arches developed at constant span length showed that the torsion constant is the most significant variable to consider when designing against LTB.
That is, the higher the torsion constant, the higher the buckling load.

5. At constant slender ratios, arches developed at $S / r_{x}=$ 60 are found to have the most resistance to LTB. That is, the lower the slender ratio, the higher the LTB load and vice versa.

6. For arches developed at constant span length, the $90^{\circ}$ and $10^{\circ}$ included angles were noted to offer the highest resistance against LTB for arches with web to flange width ratio of 2 and 3, respectively. Meanwhile, the $180^{\circ}$ included angle provided the lowest resistance against LTB. Therefore, moderate arches are expected to provide high resistance against LTB, followed by the shallow and deep arches, respectively.

7. For arches developed at constant slender ratios, the $150^{\circ}$ included angle was found to provide the highest LTB loads, that is high resistance. While shallow arches at $2 \alpha<30^{\circ}$ included angles offered the lowest resistance against LTB, and thus not suitable in design against LTB. Hence, the deep arches were stable to LTB, followed by the moderate and shallow arches, respectively.

\section{RECOMMENDATIONS}

1. While the techniques used to construct the finite element model have been tested and have demonstrated strong compatibility with current approaches, an experimental analysis should be carried out on the real test sample to supplement further the findings provided in this report.

2. The applied load case in this study was at the shear centre. Further study should be carried out with the applied load being at the top flange that will cause the 
eccentric effect common in channel sections in a realworld application.

3. Finally, the examined arches are made of structural 6061-T6 aluminium. Related research should be performed on other structural materials in order to better appreciate the inelastic lateral-torsional load behaviour at specified angles.

\section{GLOSSARY}

LTB: Lateral-torsional buckling; FEA: Finite element analysis; FE: Finite element; Al: Aluminium; 3D: Three-dimensional; CAE: Computer-aided engineering.

\section{ACKNOWLEDGEMENT}

The Vaal University of Technology supports this research work. The authors want to thank the Department of Mechanical Engineering at the Vaal University of Technology for facilitating this work.

\section{FUNDING}

This research was funded by the NRF Block grant under the guidance of the Vaal University of Technology.

\section{AVAILABILITY OF DATA AND MATERIAL}

All cited articles in this review article are available upon request.

\section{AUTHORS' CONTRIBUTIONS}

All authors jointly contributed to the development of this journal article.

\section{COMPETING INTERESTS}

The authors declare that they have no competing interests.

\section{REFERENCE}

[1] Bradford, M. A., Trahair, N. S., \& Chen, Y. Y. (2005). A further study of flexural-torsional buckling of elastic arches. International Journal of Structural Stability and Dynamics, 5(2), 163-183.

[2] BSI. (2007). BS EN 1999-1-1:2007 - Eurocode 9: Design of aluminium structures - Part 1-1: General Structural rules. In Eurocode 9. European Committee for Standardization.

[3] Ellobody Ehab, Feng Ran, \& Young Ben. (2014). Finite Element Analysis and Design of Metal Structures.

[4] Guo, Y., Zhao, S., Pi, Y., Andrew, M., \& Dou, C. (2015). An experimental study on out-of-plane inelastic buckling strength of fixed steel arches. Engineering Structures, 98(9), $118-127$. https://doi.org/10.1016/j.engstruct.2015.04.029

[5] Hulamin Extrusions. (2015). Standard Profile Catalogue.

[6] Kim, M.-Y., Min, B.-C., \& Suh, M.-W. (2000). Spatial stability of nonsymmetric thin-walled curved beams. I: Analytical approach. Journal of Engineering Mechanics, 126(5), 497-505.

[7] Liu, A., Lu, H., Fu, J., \& Pi, Y. L. (2017). Lateraltorsional buckling of fixed circular arches having a thinwalled section under a central concentrated load. ThinWalled Structures, 118(May), 46-55. https://doi.org/10.1016/j.tws.2017.05.002

[8] Lu, H., Liu, A., Pi, Y. L., Bradford, M. A., \& Fu, J. (2019). Lateral-torsional buckling of arches under an arbitrary radial point load in a thermal environment incorporating shear deformations. Engineering Structures, 179(October 2018), 189-203. https://doi.org/10.1016/j.engstruct.2018.10.071

[9] Mazzolani, F. M. (2004). Design of Aluminium Structures.

[10] Metals, A. A. S. (2012). Aluminum 6061-T6; 6061T651. ASM Material Data Sheet, 7-8.

[11] Pi, Y. L., Bradford, M. A., \& Tong, G. S. (2010). Elastic lateral-torsional buckling of circular arches subjected to a central concentrated load. International Journal of Mechanical Sciences, 52(6), 847-862. https://doi.org/10.1016/j.ijmecsci.2010.02.003

[12] Pi, Yong Lin, \& Bradford, M. A. (2003). Elasto-plastic buckling and postbuckling of arches subjected to a central load. Computers and Structures, 81(18-19), 1811-1825. 7949(03)00204-9

[13] Pi, Yong Lin, \& Bradford, M. A. (2004). Elastic flexural-torsional buckling of fixed arches. Quarterly Journal of Mechanics and Applied Mathematics, 57(4), 551-569. https://doi.org/10.1093/qjmam/57.4.551

[14] Pi, Yong Lin, \& Bradford, M. A. (2005). Out-of-plane Strength Design of Fixed Steel I-Section Arches. Engineering Structures, 131(4), 560-568. https://doi.org/10.1016/j.engstruct.2003.09.011

[15] Pi, Yong Lin, \& Trahair, N. S. (1996). Threedimensional nonlinear analysis of elastic arches. Engineering Structures, 18(1), 49-63. https://doi.org/10.1016/0141-0296(95)00039-3

[16] Pi, Yong Lin, \& Trahair, N. S. (2000). Inelastic lateral buckling strength and design of steel arches. Engineering Structures, 22(8), 993-1005. https://doi.org/10.1016/S0141-0296(99)00032-2

[17] Sadowski, A. J., Fajuyitan, O. K., \& Wang, J. (2017). A computational strategy to establish algebraic parameters for the Reference Resistance Design of metal shell structures. Advances in Engineering Software, 109, 1530. https://doi.org/10.1016/j.advengsoft.2017.02.012

[18] Snijder, H. H., Hoenderkamp, J. C. D., Bakker, M. C. M., Steenbergen, H. M. G. M., \& De Louw, C. H. M. (2008). Design rules for lateral torsional buckling of channel sections subject to web loading. Stahlbau, 77(4), 247-256. https://doi.org/10.1002/stab.200810036

[19] Spoorenberg, R. C. (2011). Structural properties and out-of-plane stability of roller bent steel arches. 
International Journal of Engineering Research and Technology. ISSN 0974-3154, Volume 13, Number 10 (2020), pp. 2851-2863

(C) International Research Publication House. https://dx.doi.org/10.37624/IJERT/13.10.2020.2851-2863

https://doi.org/10.6100/IR716581

[20] Spoorenberg, R. C., Snijder, H. H., Hoenderkamp, J. C. D., \& Beg, D. (2012). Design rules for out-of-plane stability of roller bent steel arches with FEM. Journal of Constructional Steel Research, 79, 9-21. https://doi.org/10.1016/j.jcsr.2012.07.027

[21] Tebo, E. T., Masu, L., \& Nziu, P. (2020). Effects of Factors That Influence Out-of-Plane Lateral-Torsional Buckling on Freestanding Circular Arches. Journal of Engineering, 2020, 1-12. https://doi.org/10.1155/2020/4892070

[22] Valeš, J., \& Stan, T. (2017). FEM Modelling of LateralTorsional Buckling using Shell and Solid Elements. 190, 464-471. https://doi.org/10.1016/j.proeng.2017.05.365

[23] Wang, Y. Q., Yuan, H. X., Shi, Y. J., \& Cheng, M. (2012). Lateral-torsional buckling resistance of aluminium I-beams. Thin-Walled Structures, 50(1), 2436. https://doi.org/10.1016/j.tws.2011.07.005 